\title{
CONDIÇÕES E RESTRIÇÕES NA CONSTRUÇÃO DE VIDEOAULAS COM LICENCIANDOS EM MATEMÁTICA
}

\author{
CONDITIONS AND RESTRICTIONS ON CONSTRUCTION OF \\ VIDEO LESSON WITH MATHEMATICS STUDENTS
}

\author{
LUANA LETÍCIA DA SILVA* \\ VALDIR BEZERRA DOS SANTOS JÚNIOR** \\ MARLENE ALVES DIAS***
}

\section{RESUMO}

0 objetivo deste trabalho é investigar as condições e restrições na construção de videoaulas por estudantes frequentando a disciplina de Laboratório de Matemática de uma universidade pública no curso de Licenciatura em Matemática. Esta pesquisa é objeto de um projeto mais amplo de formação de professores que investiga a relação dos futuros professores de Matemática com as tecnologias atuais. A pesquisa está fundamentada na Teoria Antropológica do Didático - TAD e as noções associadas. Para a coleta de dados, foi aplicada uma sondagem com oito questões abertas e realizada uma oficina com a participação de cinco estudantes: a oficina teve nove encontros consecutivos, nos quais o propósito era que os participantes construíssem videoaulas de Matemática com a finalidade de abordar algum conteúdo de Matemática do Ensino Fundamental - Anos Finais ou Ensino Médio. As videoaulas produzidas foram utilizadas como dados para a análise. No que concerne aos resultados da sondagem, verificamos que todos tinham familiaridade com a temática videoaulas e com o site de compartilhamento de vídeos YouTube, pois o utilizavam como ferramenta de estudo. Em relação às videoaulas construídas, os estudantes apresentaram restrições referentes ao planejamento das aulas e ao uso das ferramentas tecnológicas e, como condição, observamos que as atividades foram baseadas nas encontradas em livros didáticos, o que nos parece poder potencializar a dificuldade de planejamento de uma videoaula.

Palavras-chave: Videoaula. Condições. Restrições. Relação Pessoal.

\section{ABSTRACT}

The aim of this paper is to investigate the conditions and restrictions in the construction of video lessons by students attending to Mathematics Laboratory course in the Mathematics Undergraduate course of a public university. This research is the object of a broader teacher training project that investigates the future relation mathematics teachers will build with current technologies. The research is based on the Anthropological Theory of Didactics - ATD and other associated notions. A survey with eight open questions was applied for data collection, and a workshop with the participation of five students was conducted: the workshop had nine consecutive meetings in which the objective was for the participants to construct video lessons of Mathematics with the aim of addressing some mathematics content from Middle or High School. The video classes produced were used as data for the analysis. Regarding the survey data, we verified that everyone was familiar with video lessons and the videos hare web site YouTube, because they used it as a study tool. Regarding the constructions, the students presented restrictions regarding the planning of the classes

\footnotetext{
* Mestranda pelo Programa de Pós- Graduação em Educação em Ciências e Matemática (PPGECM- UFPE/CAA). Professora na Secretaria de Educação do Estado de Pernambuco (SEE-PE). E-mail: lua-na.leticia92@hotmail.com. Orcid: http://orcid.org/0000-0002-2261-2986

** Doutor em Educação Matemática pela Universidade Anhanguera de São Paulo. Professor no Centro Acadêmico do Agreste da Universidade Federal de Pernambuco (UFPE/CAA). E-mail: valdir.bezerra@ufpe.br. Orcid: http://orcid.org/0000-0002-3869-201X

*** Doutora em Matemática - Didática da Matemática pela Universidade Denis Diderot. Professora da Universidade Anhanguera de São Paulo (UNIAN). E-mail: maralvesdias@gmail.com. Orcid: http://orcid.org/0000-0001-9168-9066
} 
and the use of the technological tools; as a condition, we observed that the activities in the video lessons were based on those found in textbooks, which may increase the difficulty of planning a video lesson.

Keywords: Video Lesson. Conditions. Restrictions. Personal Relationship.

\section{INTRODUÇÃO}

Este trabalho iniciou-se no percurso da formação docente de licenciandos em Matemática. A oportunidade de realização dessa formação está diretamente associada ao Programa Institucional de Bolsa de Iniciação à Docência (PIBID), no qual nos propusemos a trabalhar com a elaboração de videoaulas, com foco no ensino de Matemática/Física, para alunos do Ensino Fundamental. Uma das ações do PIBID foi a proposição de uma oficina, que ocorreu em um evento, em que os participantes, estudantes de licenciatura, deveriam elaborar uma videoaula. Essa rápida experiência mostrou aos licenciandos a potencialidade dessa ferramenta didática no processo de ensino e aprendizagem de Matemática.

Observando 0 trabalho de duplas de estudantes de licenciatura, foi possível constatar que eles formulavam questões sobre as noções a serem desenvolvidas apresentadas no vídeo, que desvelavam suas dificuldades e os conhecimentos que precisavam ser revisitados. A partir dessa constatação, propusemo-nos a utilizar a temática de construção de videoaulas na formação de professores de Matemática, o que foi efetuado por meio de um projeto de pesquisa integrado a um projeto mais amplo de formação de professores. Neste projeto, as videoaulas foram consideradas como uma ferramenta de apoio didático no processo de ensino e aprendizagem de Matemática. Tomando como exemplo as videoaulas atualmente disponibilizadas na internet, verificamos, sem uma análise mais aprofundada, características que podem auxiliar nos processos de ensino e aprendizagem: a atemporalidade, facilidade de acesso e a opção de poder voltar, pausar e assistir a elas quantas vezes 0 aluno achar necessário.

Observamos aqui que, apesar de ser fácil encontrar diversas videoaulas na internet, a quantidade de pesquisas ainda é incipiente, quando tratamos do tema especificamente no campo de pesquisa em Educação Matemática. Em levantamento feito no Catálogo de Teses e Dissertações da Coordenação de Aperfeiçoamento de Pessoal de Nível Superior - CAPES, por meio da palavra-chave videoaula, encontramos oito dissertações (PATRIARCA, 2016; WARTCHOW, 2017; NASSERALA, 2014; HONÓRIO, 2017; MACEDO, 2015; SILVA, 2015; MORAIS, 2017; PONTES, 2013) e uma tese (LAMBERTI, 2014). Podemos constatar que, nestes trabalhos, as videoaulas são utilizadas para propostas de ensino na Educação Básica, no Ensino Superior e na pós-graduação Lato Sensu.

Esclarecemos que três dos trabalhos referenciados no parágrafo anterior têm como foco a formação (inicial e continuada) de professores, o que se coaduna com nossa ideia de investigar a produção de videoaulas em um curso de formação de professores. Além deste breve cenário de teses e dissertações que abordam direta ou indiretamente a temática videoaula, destacamos os artigos de: Spanhol e Spanhol (2009), cujo objetivo foi apresentar um estudo sobre como melhorar o fluxo de processos de produção de videoaulas do LED/dEGC/UFSC, ou seja, trata-se de uma pesquisa que procurou meios de melhorar as videoaulas; 0 artigo de Oliveira e Stadler (2014), que consideramos um relato de experiência, teve 0 objetivo de apresentar como os autores valem-se de videoaulas nos cursos de graduação e pós-graduação de uma universidade particular na modalidade Educação a distância (EAD) e, ainda, a dissertação de Machado (2017) buscou recorrer a videoaulas como apoio didático para os alunos em seus momentos de estudo. Atualmente, existe a intenção de se criarem 
mestrados e doutorados stricto sensu sob a forma de ensino a distância (CAPES, 2019), o que indica a necessidade de mais pesquisas sobre esse tema específico, já que as videoaulas configuram-se como uma das ferramentas neste processo.

Isso nos conduziu a considerar a importância dessa ferramenta no processo de ensino e aprendizagem, pois com a revolução das mídias digitais, é preciso repensar a escola, uma vez que surge um novo formato de ensino. Mas, para isso, também é necessário aceitar o desafio de mudança, começando pelas formações de professores, estruturas das escolas etc. (KENSKI, 2007).

Como acreditamos que serão os professores que iniciarão as mudanças indicadas por Kenski (2007), pois é a partir da prática do professor que as renovações poderão ser consolidadas, o presente trabalho se insere na perspectiva da formação de futuros professores de Matemática, uma vez que se propõe a identificar as possíveis potencialidades e dificuldades da construção e uso das videoaulas, que ultrapassem a passagem do que encontramos nos livros didáticos para os vídeos e que representem uma nova ferramenta didática no processo de ensino e aprendizagem de Matemática.

Além disso, ainda adotando como base as ideias de Kenski (2007, p.15) sobre a evolução das tecnologias: "[...] o uso do raciocínio tem garantido ao homem um processo crescente de inovações", ou seja, para a autora, as tecnologias são ascendentes à humanidade, isto é, a criatividade do homem que fez surgir as mais variadas tecnologias. A vasta expansão e o fácil acesso aos recursos tecnológicos fizeram com que o homem se adaptasse cada vez mais a esses recursos, nos mais diversos espaços, incluindo as salas de aula. Com a facilidade de acesso à internet e também do uso de smartphones, tablets, notebooks, entre outros, o número de usuários cresceu e este recurso, apesar de fazer parte do cotidiano de professores e alunos, ainda é pouco utilizado didaticamente em nossas salas de aula.

Borba et al. (2014) consideram que a velocidade com a qual as inovações tecnológicas vêm sendo implementadas faz com que se tornem um marco forte na nossa sociedade, uma vez que computadores e as demais mídias estão cada vez mais acessíveis às pessoas, sem mencionar 0 crescimento de usuários conectados com a internet. Dessa forma, acabaram surgindo versões de programas cada vez mais sofisticadas, sistemas operacionais, linguagem de programação, notebook, tablet, etc., que representam novas ferramentas que, se utilizadas adequadamente, podem auxiliar no desenvolvimento de aulas que estejam em consonância com as expectativas dos estudantes.

Sendo assim, ainda em relação ao avanço das inovações tecnológicas, podemos apontar a crescente utilização de videoaulas como ferramenta didática de auxílio ao aprendizado. Seja por meio de videoaulas gravadas exclusivamente para ambientes virtuais de aprendizagens (AVA) como, por exemplo, o Moodle, ou ainda em locais de livre acesso como os sites de compartilhamento de vídeos YouTube, Vimeo, Videolog etc.

Atualmente, entre os sites de compartilhamento, identificamos que um dos sítios mais utilizados é o YouTube, que além de ser um site de entretenimento, também pode ser considerado um aliado àqueles que querem aprender algo, ou seja, encontramos nele um potencial recurso didático se bem aproveitado. Nossa experiência com estudantes de Matemática tem mostrado que muitos deles recorrem a esse site para encontrar vídeos que os auxiliem a sanar suas dúvidas. 0 recurso de ver e rever uma videoaula quantas vezes o usuário quiser parece ser motivador para os estudantes, que o consideram apenas como um novo meio de esclarecer dúvidas que não tenham sido nem mesmo percebidas durante as aulas presenciais na Educação Básica ou Superior, mas que aparecem quando 0 estudante propõe-se a revisitar os conteúdos desenvolvidos durante as aulas, seja para se preparar para uma prova ou para resolver uma tarefa, em geral, indicada pelo professor, o que indica a 
necessidade de um tratamento mais científico desse novo recurso, mostrando meios de construção que ultrapassem a apresentação de definições e exemplos encontrados na literatura.

Importante enfatizar que a possibilidade também dada ao aluno de escolher a quais videoaulas vai assistir modifica o contrato didático (BROUSSEAU, 2010) habitual estabelecido em grande parte das salas de aula, no qual o professor costuma disponibilizar o material que deve ser estudado pelo estudante. Logo, neste momento, a responsabilidade de oferecer os materiais de estudo não cabe exclusivamente ao professor, pois o estudante passa a ter faculdade de escolha quanto aos vídeos a que vai assistir e aqueles que atendem suas necessidades.

Aliado ao potencial da ferramenta videoaula, encontramos um ambiente favorável na rede mundial de computadores. 0 número de interessados nas videoaulas de Matemática é grande, mas seria necessária uma outra pesquisa para identificar os motivos que levam os estudantes a procurarem esse material para o estudo de forma espontânea. Ressaltamos, por exemplo, a abrangência das videoaulas disponibilizadas pelo YouTube, pelo canal Vestibulândia, criado por César Medeiros, mais conhecido por nerckie ${ }^{1}$. Esse canal tem mais de 800 mil inscritos interessados em videoaulas sobre a disciplina Matemática e outras disciplinas, e já ultrapassou um milhão e meio o número de visualizações.

Como indicamos acima, as videoaulas parecem representar uma ferramenta didática importante para o estudo individual, pois nelas os estudantes podem dispor do tempo que lhes for necessário para compreender o objeto matemático em estudo, já que poderão revisitar os conteúdos sempre que 0 desejarem, imprimindo o seu próprio ritmo ao estudo e ainda podendo assumir a responsabilidade na seleção do material de estudo.

Sendo assim, diante desta possibilidade de utilização dos vídeos como ferramentas metodológicas para aprender, fundamentamo-nos nas nossas experiências e nas ideias de Kenski (2007) e Borba et al. (2014), o que nos conduziu à seguinte questão de pesquisa: Quais as condições e restrições na construção de videoaulas por licenciandos de Matemática de uma disciplina do curso de Licenciatura em Matemática de uma universidade pública de Pernambuco? A partir da questão de pesquisa, formulamos o objetivo: investigar as condições e restrições na construção de videoaulas por estudantes frequentando a disciplina de Laboratório de Matemática de uma universidade pública no curso de Licenciatura em Matemática. A opção pelo curso de Licenciatura em Matemática deve-se ao fato de que os participantes eram estudantes da disciplina de Laboratório de Matemática, em cujo plano de ensino está prevista a construção de ferramentas didáticas.

Acreditamos que a investigação das condições e restrições de produção das videoaulas pelos professores em formação nos ajudará a identificar quais são as prováveis possibilidades de inserção da videoaula como recurso didático no ensino de Matemática e, ao mesmo tempo, estaremos capacitando esses futuros professores para modificarem suas aulas, podendo assim torná-las mais motivadoras, o que também pode ser uma forma de melhorar os resultados do ensino e aprendizagem de Matemática na Educação Básica brasileira.

Cabe explicitar em qual sentido nós empregamos as palavras condições e restrições em nossa pesquisa. 0 sentido dessas palavras obedece ao que foi atribuído a elas na teoria utilizada na fundamentação teórica deste trabalho, a saber: a Teoria Antropológica do Didático, que considera a didática como a ciência que estuda certos tipos de condições e restrições que possibilitam a difusão dos conhecimentos na sociedade, permitindo assim a vida do didático nas instituições, o qual é associado ao fato de alguém ou alguma instância (pessoa ou instituição) aprender alguma coisa. Desse

1 https://www.youtube.com/user/nerckie 
modo, é preciso compreender quais as condições e restrições das videoaulas enquanto ferramenta de difusão de conhecimento na sociedade.

Sendo assim, na teoria, as duas palavras prestam-se para definir que a didática é a ciência das condições e restrições da difusão do conhecimento. Em linhas gerais, Chevallard (2010) indica que, na TAD, só existiriam as condições para a difusão do conhecimento, no entanto, quando consideramos uma determinada posição dentro de certo tipo de instituição, podemos ter em vista as restrições impostas por essa instituição. Em nosso trabalho, levamos em conta a posição ocupada pela temática videoaula dentro da instituição formação de professores, o que nos possibilita realizar uma análise das condições e restrições para o desenvolvimento das videoaulas por estudantes em formação.

Além disso, é preciso considerar em que nível podemos identificar essas condições e restrições, o que está associado aos níveis de codeterminação, que tornam possível analisar o papel do professor, do estudante, dos responsáveis pelo sistema escolar, das propostas de ensino, da política, da sociedade, da civilização e da humanidade na concepção e implementação de sistemas didáticos, sendo esse último a reunião de estudantes, professor(es) e um desafio didático.

Para 0 objeto da pesquisa "videoaulas de Matemática", o estudo das condições e restrições proposto na pesquisa está relacionado às mudanças na sociedade, uma vez que as novas tecnologias transformaram as formas de relacionamento da sociedade, o que conduz a modificações em todos os outros níveis.

\section{REFERENCIAL TEÓRICO}

Após considerar nossa problemática e definir o objetivo da pesquisa, optamos como fundamentação teórica para o desenvolvimento deste trabalho pela Teoria Antropológica do Didático (TAD). Importante esclarecer que não é nosso objetivo detalhar a teoria em todos os seus princípios, por isso apresentamos aqueles diretamente presentes na análise, a saber: relação pessoal e relação institucional, praxeologias, objetos ostensivos e não ostensivos e níveis de codeterminação.

Iniciamos destacando o que Chevallard (2009) denomina como relação pessoal de um indivíduo $x$ com um objeto 0 , simbolicamente indicada por $R(x, 0)$. Tal relação representa todas as interações que $x$ pode ter com um objeto 0 , tais como: manipulá-lo, falar com ou sobre 0 objeto, sonhar com ele etc. Podemos concluir então que um objeto 0 existe para $x$ se a relação pessoal de $x$ com 0 é não vazia $(R(x, 0) \neq \emptyset)$. No contexto deste trabalho, podemos exemplificar que investigamos a relação pessoal que os estudantes de um curso de Licenciatura em Matemática, participantes da disciplina Laboratório de Matemática, têm com os objetos videoaula, Matemática, etc.

Podemos afirmar ainda que a relação pessoal de $x$ a um objeto $o$ muda ou se cria, caso ela ainda não exista para $x$, com 0 encontro de $x$ com 0 objeto 0 nas instituições $/$ onde ele vive e onde $x$ vem ocupar uma posição $p$, que o põe em contato direto com $o$ (CHEVALLARD, 2009).

Desse modo, dado um objeto 0 , uma instituição $I$, e uma posição $p$ em $I$, podemos chamar de relação institucional de 0 em relação à $p$, e registramos como $R_{l}(p ; 0)$, a relação ao objeto 0 que deverá ser, idealmente, daqueles sujeitos de $I$ em posição $p$. Se afirmamos que $x$ é um bom sujeito da instituição I em posição $p$, simbolicamente isto quer dizer que $R(x ; 0) \equiv R_{l}(p ; 0)$, na qual 0 símbolo $\equiv$ designa a conformidade da relação pessoal de $x$ à relação institucional a 0 em posição $p$ (CHEVALLARD, 2009). Por exemplo, no nosso estudo, os estudantes já dispõem de uma relação pessoal com o objeto videoaula, adquirida por meio de sua relação com a instituição YouTube. Ao participarem da pesquisa, esses mesmos estudantes podem mudar sua relação com 
0 objeto videoaula e simultaneamente com a Matemática, pois podem buscar novos meios para 0 desenvolvimento de suas aulas.

Para compreender como as relações pessoais e institucionais formam-se e/ou modificam-se, Chevallard (2009) admite que toda atividade humana, regularmente cumprida, pode ser considerada como a aplicação de um modelo mais amplo denominado praxeologia. A noção de praxeologia assume papel de destaque na TAD, pois generaliza diferentes noções culturais como, por exemplo, concepções, competências etc. Além disso, a noção de praxeologia não especifica a atividade matemática de modo a distingui-las de outras atividades humanas, ou seja, as especificidades da Matemática devem ser reconhecidas de outra maneira.

Uma praxeologia (modelo para representar as atividades humanas) pode ser entendida em dois blocos: saber-fazer (praxis) e o saber (logos). 0 bloco do saber-fazer é composto pelos tipos de tarefas e técnicas e o bloco do saber, por tecnologia e teoria. Desse modo, podemos afirmar que uma praxeologia, em sua forma mais simples, é assim composta: por um tipo de tarefa T, por pelo menos uma técnica $\tau$, maneira de realizar as tarefas $t$ do tipo $T$, de uma tecnologia $\theta$ associada a cada técnica, que corresponde a um discurso racional (logos) sobre a técnica (tekhnê) que tenta tornar $\tau$ inteligível como meio de cumprir as tarefas do tipo T - e de uma componente teórica $\Theta$, que pode ser compreendida como a tecnologia da tecnologia $\theta$, portanto o conjunto de componentes, representado pela quádrupla $[T, \tau, \theta, \Theta]$ corresponde a uma praxeologia (CHEVALLARD, 2009).

Podemos exemplificar uma praxeologia tomando como base uma situação exposta por Chevallard (2009) com o tipo de tarefa: dividir um número inteiro por outro, por exemplo, 509 dividido por 15 é uma tarefa deste tipo. Para descrever os outros elementos praxeológicos, ele afirma: "Certa técnica $\tau$ conduz então, no caso de t, a fazer isto: porque $15=3 \times 5$, dividimos 509 por 5 , 0 que leva a dividir 505 por 5, 0 quociente é 101, é então dividido por 3, o que leva a dividir 99 por 3: obtemos finalmente 33, que é o quociente procurado" (CHEVALLARD, 2009, p. 5).

Se observarmos a técnica executada por Chevallard (2009), verificamos que ela não é habitualmente utilizada, quando pensamos em dividir números inteiros e a falta de um bloco tecnológico-teórico faz com que possamos duvidar por algum instante da eficácia da técnica proposta. Podemos justificar esta técnica ressaltando que ela considera a decomposição do divisor em fatores primos e a divisão do dividendo por um desses fatores, para, na sequência, dividir o quociente encontrado pelo outro fator, assim sucessivamente até encontrar o resultado da divisão, o que podemos considerar como a tecnologia da técnica. Em seu trabalho, Chevallard (2009) propõe aos leitores que tomem este exemplo com uma experiência para (re)construir o bloco tecnológico-teórico da técnica exposta.

0 que podemos ainda destacar do exemplo proposto é que, quando dispomos da técnica anterior, a nossa relação com o objeto "quociente" muda de alguma forma, pois é possível descobrir nessa técnica um novo caminho que não tínhamos imaginado (CHEVALLARD, 2009). Um ponto que poderíamos nos indagar é de como são feitas as técnicas e de que ingredientes ela é composta? Para sanar estes questionamentos, Chevallard (1994) propõe a distinção entre dois tipos de objetos que ajudam a entender a técnica: os ostensivos e os não ostensivos.

Sendo assim, segundo o pesquisador, um objeto ostensivo é aquele que tem sua forma material, sensível, como, por exemplo, uma caneta, um compasso, ou os gestos, as palavras, os esquemas, os desenhos, os grafismos, as escritas e os formalismos, ou seja, tudo que possa ser manipulado no sentido estrito, como a caneta, e no sentido amplo por meio do falar, olhar, gesticular, desenhar, entre outros (CHEVALLARD, 1994). Os não ostensivos, ao contrário dos ostensivos, não podem ser manipulados, mas somente evocados por meio da manipulação dos ostensivos, por exemplo, o não 
ostensivo fórmula do montante de uma capitalização composta é evocado, quando tratamos de manipular o ostensivo algébrico $\mathrm{M}=\mathrm{C} .(1+\mathrm{i})^{\mathrm{t}}$, ou seja, não podemos separar o manipular do evocar, pois a manipulação dos ostensivos é regrada principalmente pelos não ostensivos e os não ostensivos são evocados com a ajuda dos ostensivos, o que indica a existência de uma dialética necessária entre ostensivos e não ostensivos. No exemplo da fórmula do montante numa capitalização composta, as noções de capital, montante, juros, tempo, adição, potenciação e multiplicação correspondem aos ostensivos e não ostensivos, que permitem identificar as regras de manipulação do ostensivo fórmula do montante. Os exemplos considerados mostram a importância de explorarmos diferentes ostensivos na construção de uma videoaula e como a noção de praxeologia possibilita a integração das justificativas para as técnicas utilizadas, relacionando o saber fazer com 0 saber.

Acreditamos ser importante considerar também a exposição dos níveis de codeterminação propostos pela TAD. Esta noção é uma escala elaborada para 0 estudo das condições e restrições na difusão das praxeologias ou de maneira análoga da difusão do conhecimento. Os níveis são organizados da seguinte forma: tópicos $\leftrightarrow$ temas $\leftrightarrow$ setores $\leftrightarrow$ domínios $\leftrightarrow$ disciplinas $\leftrightarrow$ pedagogia $\leftrightarrow$ escola $\leftrightarrow$ sociedade $\leftrightarrow$ civilização (CHEVALLARD, 2007). 0 nível tópico é considerado como 0 nível mais baixo e 0 civilização, como o mais alto.

Junto ao nível tópico, os níveis temas, setores e domínio constituem a camada mais baixa na escala. Se pensamos nos níveis tópico, temas e setores a partir de uma escala de codeterminação didática, podemos comparar o nível tópico a uma praxeologia pontual que pode ser aquela relacionada a um determinado tipo de tarefa. Já o nível tema corresponde à praxeologia local e compreende as técnicas utilizadas para realizar o tipo de tarefa da praxeologia pontual e as tecnologias que a justificam. 0 nível setor corresponde à praxeologia regional, que compreende a teoria que justifica as tecnologias, as quais, por sua vez, servem para justificar as técnicas.

Considerando o espaço para a produção deste trabalho, damos ênfase aos níveis inferiores da escala de codeterminação, no entanto sabemos que uma mudança em qualquer um dos níveis interfere diretamente nos outros, mesmo nos níveis mais superiores. Em relação ao exercício docente, Chevallard (2002) afirma que os professores geralmente restringem-se aos níveis tópicos e temas. Tal situação leva de certa forma a um trabalho na docência que pouco motiva os estudantes, pois as tarefas que podem motivá-los estão localizadas nos níveis setores e domínios. Essa ressalva de Chevallard nos indica um elemento importante que pode causar restrições quando do estudo de uma determinada noção matemática.

\section{PERCURSO METODOLÓGICO}

Para cumprir nosso objetivo, realizamos uma pesquisa qualitativa que, segundo Godoy (1995), nos possibilita estudar fenômenos que envolvem seres humanos e suas relações sociais constituídas em vários ambientes, de forma que, para 0 estudo do fenômeno, o pesquisador busca entender 0 fenômeno, considerando as pessoas nele envolvidas e os pontos de vista relevantes. Desse modo, parte-se de questões amplas que se esclarecem no desenvolvimento do estudo, que pode seguir diferentes caminhos.

Os participantes da pesquisa são estudantes cursando o componente curricular eletivo Laboratório de Matemática do oitavo período do curso de Licenciatura em Matemática, de uma universidade pública brasileira. São sete estudantes matriculados, mas apenas cinco participaram da pesquisa. A escolha da disciplina eletiva Laboratório de Matemática como campo de pesquisa deu-se pelo fato de poder 
relacionar a oficina com a ementa que a disciplina propunha. Além disso, é importante ressaltar que a infraestrutura do Laboratório de Ensino de Matemática foi mais um dos fatores que justificam a escolha, uma vez que nele dispúnhamos de computadores com os softwares necessários para a construção das videoaulas.

Como já indicado na introdução, construímos uma oficina que serviu de base para o desenvolvimento da pesquisa. A oficina intitulada Mídias digitais e videoaulas: construindo ferramentas de apoio didático no ensino de Matemática objetivou apresentar a futuros professores de Matemática 0 uso da tecnologia no ensino, em particular as videoaulas, como um suporte didático no processo de ensino e aprendizagem. Para sua realização, foram necessários nove encontros presenciais de uma hora e quarenta minutos cada.

Nos encontros, foram desenvolvidas diferentes situações, a saber: no primeiro encontro, foi aplicada uma sondagem por meio de um questionário com oito questões abertas, com 0 intuito de verificar a familiaridade dos participantes com a temática videoaulas; em seguida, foram apresentados alguns pontos primordiais antes de iniciarmos as construções: explicitamos o que seriam as mídias digitais, o conceito de videoaula, as etapas necessárias para sua construção e alguns tipos de videoaulas disponibilizadas na internet. Ainda no primeiro encontro, foram apresentados alguns softwares que poderiam ser utilizados para a construção das videoaulas.

As videoaulas construídas pelos participantes da oficina foram do tipo lousa virtual, ou seja, quando se faz uso de mesas digitalizadoras. Para a construção dessas videoaulas, quatro participantes utilizaram a mesa Wacom CTL 480L IntuosPequena e um participante utilizou a Wacom Bamboo CTL-470. Essas mesas possuíam além da mesa gráfica, acompanhavam de uma caneta sem bateria que funcionava com o método de ressonância eletromagnética, um cabo USB, pontas de caneta para reposição e um CDcom instruções de instalação do software de utilização do produto. A diferença entre as mesas era a sensibilidade da caneta e 0 tamanho delas, ressaltamos que, essa diferenciação dos modelos não interferiu na produção das videoaulas pelos participantes. Além da utilização da mesa digital, foram utilizados notebooks, fones de ouvido com microfone, e os softwares AtubeCatcher ${ }^{2}$, Xourna/ ${ }^{3}$ e Windows MovieMaker ${ }^{4}$. Na sequência, os participantes elaboraram um planejamento para a construção da videoaula. Nesse planejamento, a escolha do tema a abordar era livre, mas restrita aos temas relacionados com o ensino de Matemática dos Anos Finais do Ensino Fundamental ou Ensino Médio.

No segundo encontro, os participantes que ainda não haviam concluído o planejamento da videoaula puderam terminá-Io na aula e, na sequência, começaram a utilizar as mídias digitais, momento em que foi necessário um trabalho mais específico sobre como manusear a mesa digitalizadora. No terceiro e quarto, foram desenvolvidas as videoaulas e alguns participantes editaram seus vídeos utilizando o programa Windows MovieMaker.

No quinto encontro, foi realizada uma apresentação prévia das videoaulas construídas pelos participantes e 0 grupo fez comentários e sugestões com 0 objetivo de melhorar as apresentações. No sexto encontro, a partir dos comentários e sugestões, alguns participantes regravaram suas videoaulas.

No sétimo e oitavo encontros, fizemos ainda considerações sobre videoaulas que ainda não haviam sido editadas e as concluídas foram publicadas no YouTube. Aqueles que tinham publicado suas

2 Programa utilizado para baixar vídeos do Youtube, converter arquivos para outros formatos, extrair apenas a faixa de áudio em MP3 de vídeos, captura de tela e áudio simultaneamente e redimensionamento de vídeos.

3 Programa utilizado para anotações, marcações coloridas ou lembretes num arquivo que parecem páginas de caderno.

4 Programa de edição de vídeos da Microsoft que permite a inserção de efeitos de transição de vídeos. 
videoaulas iniciaram o questionário final, com três questões abertas, que foi concluído por todos no nono e último encontro.

Destacamos ainda que as ações metodológicas aplicadas no desenvolvimento da pesquisa tinham como finalidade atingir 0 objetivo geral da pesquisa, que é investigar as condições e restrições na construção de videoaulas por estudantes frequentando a disciplina de Laboratório de Matemática de uma universidade pública no curso de Licenciatura em Matemática.

A ação de realizar uma sondagem, por meio de um questionário, foi de grande valia, porque pudemos compreender a proximidade dos estudantes de um curso de formação de professores com as videoaulas, antes mesmo de participarem da oficina proposta na pesquisa. A videoaula que cada estudante construiu, na oficina, foi também agregada aos dados para a análise, uma vez que suas produções deixavam transparecer as praxeologias matemáticas consideradas. E, por fim, a ação de aplicar um questionário, com três questões abertas, nos encontros finais das oficinas, justifica-se pelo fato de que buscávamos identificar como os estudantes haviam vivenciado a experiência.

\section{ANÁLISE DOS DADOS}

Apresentamos a análise em três partes: na primeira, discutimos a sondagem realizada com os participantes da pesquisa antes da aplicação da oficina. Na segunda parte, analisamos as videoaulas construídas pelos participantes, identificando as praxeologias matemáticas utilizadas nas videoaulas e indicando as dificuldades encontradas, observando se estavam relacionadas a alguma restrição. $\mathrm{Na}$ terceira e última parte, analisamos as respostas dos participantes da pesquisa ao questionário e tentamos identificar a relação pessoal dos mesmos sobre 0 interesse, a importância e a aplicabilidade das videoaulas após a construção desse tipo de ferramenta didática. Frisamos que neste artigo iremos ressaltar apenas alguns pontos que mais nos chamaram a atenção em relação aos dados coletados.

\section{ANÁLISE DA SONDAGEM}

Na sondagem feita com os participantes da pesquisa, verificamos o reconhecimento deles com 0 tema videoaulas. Identificamos qual a relação pessoal (CHEVALLARD, 2009) que mantinham com 0 objeto videoaula. Na primeira questão da sondagem: "Você utiliza ou já utilizou videoaulas disponibilizadas pela internet? Se sim, em quais disciplinas?", todos os estudantes responderam que já haviam utilizado videoaulas disponibilizadas na internet, relativas às disciplinas específicas da Matemática, por exemplo, conteúdos associados ao Cálculo Diferencial e Integral, Teoria dos Números, Álgebra Linear etc. Na segunda questão, que completa a primeira, indagamos quais os sites/canais mais utilizados por aqueles que assistem. Todos mencionaram 0 site YouTube.

$\mathrm{Na}$ terceira questão,"Quais são os sites/canais a que você mais assiste?”, observamos que três estudantes responderam apenas em relação ao site YouTube, um deles respondeu: "assisto a vários vídeos do Youtube, procuro aleatoriamente, se gostar continuo" e outro foi mais específico, indicando os canais "Me Salva e o Matemático". Nesta questão, concluímos que os participantes não sabiam diferenciar site e canal, mas todos utilizam o site do YouTube para assistir a videoaulas.

Na quarta questão da sondagem, tentamos compreender, na percepção dos participantes, quais os pontos positivos e negativos das videoaulas acessadas por eles. Tivemos várias respostas distintas, mas destacamos apenas duas delas: aquelas em que os estudantes apresentam uma visão positiva das videoaulas: "possibilitam aulas de revisão e de aprofundamento sem ser 
necessariamente com o livro/apostila" e "positivo é que posso rever o que passou despercebido durante a aula". Os comentários desses participantes indicam que eles veem as videoaulas como uma forma de revisitar o conteúdo que foi tratado em sala sem utilizar livros e apostilas.

Já, ao comentarem sobre os pontos negativos desses vídeos, um participante disse: "já encontrei equívocos em algumas respostas". A partir desse comentário, podemos perceber que ao mesmo tempo em que os estudantes recorrem às videoaulas, eles são capazes de avaliar e criticar o conteúdo apresentado, o que sinaliza um novo meio de trabalhar com estudantes da licenciatura, que podem assistir a videoaulas e apresentar suas sugestões e indicações, como por exemplo, o YouTube Educação que, mesmo sendo um site com videoaulas de melhor qualidade, parece ser desconhecido dos estudantes.

Com a quinta questão, procuramos entender por quais motivos os participantes recorriam às videoaulas. Tivemos várias respostas diferentes e interessantes, dentre elas: "por não entender o material e/ou aulas dadas pelos professores". Aqui podemos supor que os participantes estão habituados a receber apenas materiais impressos, em particular, livros e apostilas, não usufruindo das tecnologias como recurso didático. Delineia-se a necessidade de uma nova relação pessoal dos professores de forma a questionar e mudar a relação institucional existente, quando se considera a organização didática de suas aulas, o que parece indicar a importância de o professor ter uma participação maior no nível pedagogia, em geral, deixado apenas a cargo dos especialistas.

Chama atenção a resposta de um participante: "pelo fato de poder parar e voltar quantas vezes for necessário", que traduz a importância da videoaula para sanar possíveis dúvidas, uma vez que é possível assistir a ela por diversas vezes, o que mostra o valor dessa ferramenta didática ao contribuir para que os estudantes desenvolvam seus próprios ritmos de estudo.

Com a sexta questão, questionamos aos participantes se eles ficavam com dúvidas após assistirem a uma videoaula e, em caso afirmativo, a quem eles recorriam. Todos os participantes responderam que sim, mas que nem sempre isso acontecia, um dos participantes ressaltou "nesses casos, como já mencionei na pergunta 04 - acabo não tendo como dialogar por falta de um ambiente para isso. Ficando assim na dúvida e/ou recorrendo a professores presenciais". Tal extrato remete à necessidade de um ambiente para discussões, isto é, a importância de um mediador que possa compreender as dificuldades encontradas e ajudar os estudantes a saná-las. Em geral, esses ambientes são disponibilizados por meio de chats ou fóruns para discussão em ambientes educacionais. $\mathrm{Na}$ realidade, rever conteúdo sem meios para sanar dúvidas, em geral, não produz resultado. Aqui, nos parece importante lembrar que não basta criar chats ou fóruns, é preciso ter um responsável que tenha conhecimentos do tema, setor e domínio para sanar as dúvidas.

Com a sétima questão 7 , buscamos compreender qual 0 critério de escolha de uma videoaula e, entre as respostas, encontramos: produzidos por professores que são referência, a qualidade da videoaula e a forma como ela é apresentada. Finalmente, na questão 8, os participantes puderam sugerir, opinar, criticar sobre o tema em questão e um deles respondeu "ter atenção na qualidade do áudio e vídeo", alertando sobre possíveis problemas conceituais que estes vídeos podem conter. Mais uma vez foi possível observar que os estudantes, ao assistirem às videoaulas sobre temas conhecidos, mesmo não sendo especialistas, são capazes de avaliar e criticar as aulas apresentadas, mostrando suas deficiências. Eles mostram-se capazes de ultrapassar os níveis tópicos e temas para domínios e setores por eles conhecidos, buscando explicações que ultrapassam a simples aplicação de uma técnica.

Verificamos, na sondagem, que as videoaulas são consideradas pelos estudantes como um meio interessante de busca pelo aprendizado. As condições que elas proporcionam em aprender, como: possibilidade da escolha das videoaulas, atemporalidade para assistir à videoaula; videoaulas 
como suporte para o estudo, sinalizam alguns possíveis benefícios para a utilização das videoaulas no contexto educacional. Cabe ressaltar que estas condições corroboram o que havíamos observado em nossa revisão de literatura: o recurso videoaula pode ser mais explorado no contexto educacional.

Além disso, podemos elencar algumas restrições mencionadas pelos estudantes, como: qualidade técnica do vídeo e noções matemáticas abordadas não serem "confiáveis". Acreditamos que a última restrição, quando considerada pelos estudantes, é benéfica e mostra que eles podem não assistir aos vídeos de modo passivo; podem fazê-lo com uma visão crítica.

\section{ANÁLISE DAS VIDEOAULAS}

Em relação às videoaulas construídas pelos participantes da pesquisa, em razão do espaço reduzido para este trabalho, apresentamos, como exemplo, apenas uma delas com mais detalhes. Na figura 1, é possível ver a tela da videoaula construída pelo Aluno A, que teve como temática área de figuras planas.

Figura 1 - llustração de um trecho da videoaula do Aluno A.

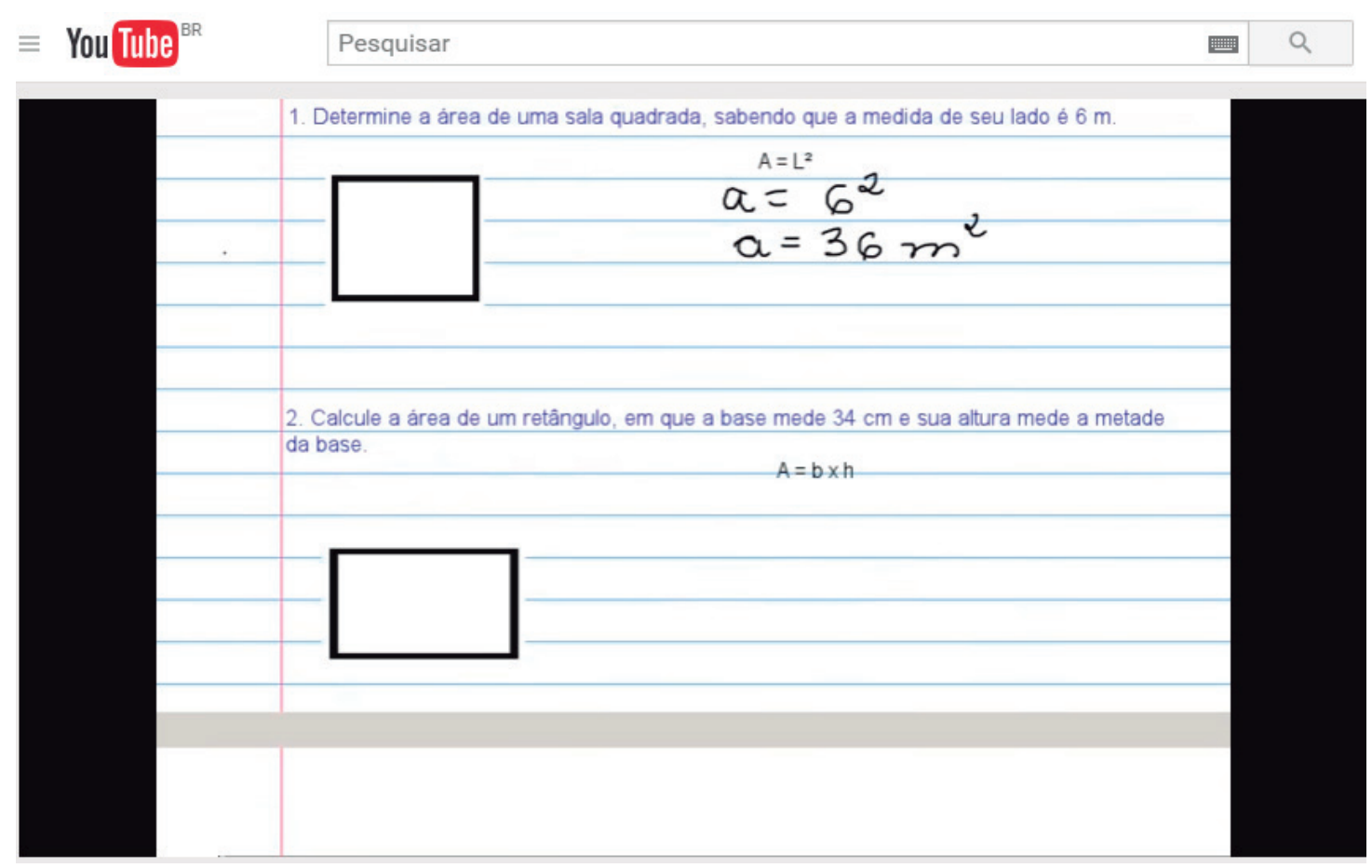

Fonte: Dados da pesquisa.

0 aluno A utilizou as ferramentas apresentadas na oficina, a saber: o software Xournal, a mesa digitalizadora e o editor de vídeos Windows MovieMaker. Analisamos a temática abordada pelo aluno A por meio da noção de praxeologia. Nesta análise foi possível observar cinco praxeologias: Tipo de tarefa: Apresentar o conceito de área de figuras planas. Técnica: Utilizou quadrados de $1 \mathrm{~m}^{2}$ para representar um padrão de medida para as demais áreas.; Tipo de tarefa ${ }_{B}$ : Calcular a área de um quadrado. Técnica: Utilizou a fórmula $A=1^{2}$ para calcular a área do quadrado; Tipo de tarefa ${ }_{c}$ : Calcular 
a área de um retângulo. Técnica: Utilizou a fórmula $A=$ bxh; Tipo de tarefa ${ }_{D}$ : Calcular a área de um losango. Técnica: Utilizou a fórmula $A=\mathrm{dxD} / 2$.; Tipo de tarefa $_{E}$ : Calcular a área de um trapézio. Técnica: Utilizou a fórmula (bxB)xh/2. Já o bloco do saber foi o mesmo para as cincos praxeologias: Tecnologia: Cálculo de medida de área. Teoria: Geometria euclidiana plana.

Ainda em função das praxeologias identificadas na videoaula construída pelo aluno A, podemos, a partir da produção do aluno na videoaula, observar que sua relação pessoal com a noção área de figuras, quando o objetivo era lecioná-la, consistiu em organizá-la em exemplos, que correspondem às praxeologias usuais encontradas em livros didáticos. Essa estratégia tende a mostrar que esse aluno ainda está preso à relação institucional que parece ser a dos cursos por ele frequentados. Sua opção foi identificar apenas área de quadriláteros e apresentar a fórmula de cálculo, não considerando outras figuras geométricas nem outras técnicas. Essa escolha pode também estar associada à falta de familiaridade com a apresentação de trabalhos em forma de videoaula e à restrição em relação ao tempo de duração do vídeo.

Outra observação válida é que 0 aluno $\mathrm{A}$ considera que quem assiste à videoaula fará associação dos objetos ostensivos algébricos ( aos objetos ostensivos geométricos (retângulo ou a figura de um retângulo) sem a necessidade de referir-se a esta associação, 0 que tende a reforçar a ideia de que 0 aluno transferiu para 0 vídeo a forma de trabalho que parece ser a vigente nas relações institucionais por ele vivenciadas. Ressaltamos aqui que, apesar de se tratar de um curso de Licenciatura em Matemática, 0 aluno não considera a importância de mostrar a passagem do objeto ostensivo figural para o objeto ostensivo fórmula.

Certamente, nas técnicas apresentadas pelos outros participantes da pesquisa, era necessária a manipulação de objetos ostensivos, que também foi considerada sem levar em conta a importância da explicitação da passagem de um objeto ostensivo ao outro. Essa passagem ainda é tida como autoevidente, o que pode tornar-se uma restrição para a compreensão do objeto matemático, que está associado a diferentes objetos ostensivos, necessitando do objeto ostensivo oral que justifique a utilização daquele que será mais adequado para a resolução da tarefa proposta.

Além das restrições acima, observamos na construção da aula do Aluno A, que a aula era estática, o que parece indicar que este aluno tem pouco contato com softwares como 0 Geogebra. Os softwares poderiam enriquecer a apresentação; mas para isso é preciso criar novas praxeologias, 0 que parece ainda ser uma dificuldade, pois os outros participantes mantiveram a apresentação clássica: definições, exemplos e exercícios, reforçando a percepção de que as aulas do curso seguem, em geral, o modelo denominado por Chevallard (2011) de paradigma de visita às obras.

Outra situação que indica a inserção dos estudantes no paradigma de visita às obras (CHEVALLARD, 2011) remete aos problemas e questões propostos pelos estudantes em suas videoaulas. Estes foram problemas e questões que não privilegiavam o percurso de busca da resposta, ou seja, a preocupação não estava no estudo do caminho para chegar à resposta, pelo contrário 0 que se mostrava importante era só a resposta final. Além disso, as atividades propostas eram focadas em praxeologias pontuais, nas quais havia mais preocupação com a técnica para os tipos de tarefas apresentadas, sem muito destaque às tecnologias que as justificavam, isto é, a praxelogia era centrada na aplicação de uma técnica. Isso corrobora a afirmação de Chevallard (2002) no sentido de que, na maioria das vezes, os professores restringem-se aos dois níveis mais inferiores na escala de coderteminação e aos alunos 0 estudo de tipos de tarefas semelhantes às apresentadas pelo professor.

Ressaltamos, finalmente, que os participantes da pesquisa consideram o recurso videoaula como um novo meio para estudar temas matemáticos, o que nos conduz a nos questionarmos sobre 
os tipos de videoaulas disponíveis na internet, pois os mesmos estudantes que utilizam videoaulas para estudar parecem ter encontrado apenas vídeos que revisitam as obras existentes nos livros didáticos e apostilas, agregando pouca ou nenhuma novidade, reforçando o paradigma de visita às obras já explicitado, isto é, uma visita sem questionamentos igualada à visita de um museu, onde 0 guia apresenta as obras e 0 visitante às contempla.

A análise das videoaulas construídas pelos estudantes revela a necessidade de se proporem novas metodologias no desenvolvimento do processo de ensino e aprendizagem, em particular na formação de futuros professores, pois estes tendem a reproduzir as aulas a que mais se adaptaram.

\section{ANÁLISE DE QUESTIONÁRIO FINAL}

Nos últimos encontros da oficina proposta, aplicamos um questionário final. Nele, propusemos que os estudantes respondessem a três questões abertas (Quadro 1), cujo objetivo foi identificar como se deu a vivência deles nas oficinas e qual a influência dessa vivência sobre suas relações pessoais, que eram a do ensino tradicional, centrado em definições, exemplos e exercícios associados a um livro didático ou a uma apostila.

Quadro 1 - Itens 1,2 e 3 do questionário final.

1. Qual(is) a(s) principal(is) dificuldade(s) encontrada(s) durante a construção das videoaulas?

2. Qual(is) a(s) potencialidade(s) que as videoaulas oferecem para o processo de ensino e aprendizagem?

3. Comentários gerais sobre a construção de videoaula para o ensino de Matemática (opiniões, ideias etc)

Fonte: Os autores

Ao analisarmos a questão 1, observamos que 0 Aluno A apresentou como principal dificuldade "usar a mesa digitalizadora, preparar a aula, regular as vozes", sendo duas delas relacionadas com as ferramentas utilizadas para a construção da videoaula. Mas preparar a aula parece ser um elemento importante para os estudantes de licenciatura que já deveriam estar mais familiarizados com conceitos e noções relativos às pesquisas em Educação Matemática.

Na resposta do Aluno E, "exige muito tempo para o planejamento e edição da videoaula, escrever letra legível na lousa digital", observamos que implicitamente este participante indica a importância de o professor dispor de tempo para preparar suas aulas, o que muitas vezes parece estar sendo o papel do livro didático, o qual é reproduzido sem reflexão.

Os alunos $\mathrm{B}$ e $\mathrm{C}$ manifestaram que suas dificuldades estavam restritas apenas as ferramentas utilizadas, justificando respectivamente que "o trabalho com alguns programas, ainda desconhecidos" e "dificuldade na escrita durante a utilização da mesa digital...", porém suas produções seguiram o mesmo caminho dos outros participantes da pesquisa, o que parece indicar a força do paradigma de visita às obras.

0 Aluno $\mathrm{D}$ também mencionou a dificuldade em manusear a mesa digitalizadora. Isso sinaliza, portanto, que não basta saber da existência de determinados softwares ou mídias digitais. Para que possamos trabalhar com estes recursos, é necessário conhecer novas metodologias que permitam construir videoaulas dinâmicas e que motivem os estudantes, não as reduzindo simplesmente a um estudo oral e visual do material existente nos livros didáticos. 
Observamos que, se desejamos formar estudantes que proponham aulas que ultrapassem 0 paradigma de visita às obras, é preciso que os professores dos cursos de Licenciatura em Matemática utilizem novas metodologias em suas aulas, visto que os resultados do diagnóstico possibilitam observar que os estudantes reproduzem o que aprenderam nos cursos de formação. Após a introdução de novas metodologias de ensino e de estudo de alguns softwares, é preciso construir, na prática, videoaulas, cujo objetivo seja responder a uma questão geradora suficientemente ampla para vencer as restrições já indicadas nas respostas dos participantes da pesquisa. Certamente, é um trabalho árduo que precisa ser considerado pelos formadores de professores.

De modo geral, podemos classificar as dificuldades citadas do item 1 segundo 0 quadro 2.

Quadro 2 - Dificuldades dos participantes durante a construção das videoaulas

\begin{tabular}{|l|l|}
\hline Dificuldades encontradas durante a construção das videoaulas. & Alunos \\
\hline Dificuldades com as ferramentas & A, B, C, D e E. \\
\hline Dificuldades didáticas & A, D e E \\
\hline Dificuldades pessoais & D \\
\hline
\end{tabular}

Fonte: Os autores.

Na questão 2, foi pedido para identificar possíveis potencialidades das videoaulas. 0 objetivo era verificar se os participantes da pesquisa enxergaram condições que elas poderiam oferecer para auxiliar no processo de ensino e aprendizagem de Matemática. Os alunos A, B, C e E ressaltaram a questão da atemporalidade que as videoaulas oferecem, já para 0 aluno $D$, as videoaulas podem ser um complemento das aulas presenciais. A resposta do aluno $D$ aponta a possibilidade de que as videoaulas sejam consideradas para compor o sistema didático que não se resume à sala de aula. Este tipo de sistema didático é atualmente comum de ser encontrado em cursos de nível superior que são oferecidos em Ambientes Virtuais de Aprendizagem, mas certamente é preciso estudos que mostrem como melhorar esses ambientes, que não podem limitar-se à apresentação oral e visual das mesmas praxeologias desenvolvidas em livros didáticos.

Na última questão, que era aberta para comentários dos estudantes, eles reafirmavam o uso da videoaula como uma estratégia didática para o complemento das ações desenvolvidas em sala de aula, mas sem argumentação sobre como elas podem modificar o que se faz habitualmente.

Ressaltamos ainda a resposta do aluno $\mathrm{E}$, que considera importante 0 estudo sobre a construção de videoaulas na formação inicial e continuada de professores, o que para o aluno B poderá ser mais uma ferramenta para a sua prática docente.

A análise das respostas dos estudantes para as três questões finais revela que a relação pessoal desses estudantes com a Matemática está associada à relação institucional existente, na qual 0 professor é detentor do saber. 0 papel dos estudantes é apenas o de reprodutor de praxeologias prescritas nos livros didáticos e nos materiais de estudo indicados pelo professor. Da mesma forma, a atuação do professor é controlada pelas condições e restrições apresentadas nos planos de ensino, que seguem as diretrizes construídas pelos especialistas sob a ótica da política vigente, que pode não estar em consonância com as expectativas da sociedade e que, em geral, dá pouco crédito às pesquisas existentes, dificultando a implantação de novas metodologias nas quais 0 aluno seja 0 
responsável pela construção de seu próprio conhecimento, o que provocaria mudanças em todos os níveis da escala de codeterminação.

\section{ALGUMAS CONSIDERAÇÕES}

Em relação às videoaulas construídas pelos participantes, as praxeologias evidenciadas seguem 0 modelo de aula tradicional, repetindo praxeologias existentes em livros didáticos e considerando os ostensivos utilizados para a exposição da temática escolhida como autoevidentes, como ocorre nas aulas presenciais.

Essa forma de trabalho parece estar associada ao formato das videoaulas que, em sua maioria, são construídas com base nas aulas tradicionais e a falta de pesquisas específicas, em particular, sobre novos modelos teóricos que possibilitem uma participação mais ativa dos estudantes, respeitando seus ritmos e dando condições para que eles compreendam a importância de um trabalho autônomo, no qual o professor é apenas o orientador que os auxilia no caso de dificuldades difíceis de serem ultrapassadas por meio do estudo das respostas existentes na literatura do conteúdo que está sendo discutido.

É interessante observar que a Licenciatura em Matemática parece ainda distante das pesquisas em Educação Matemática, pois os estudantes ainda reproduzem as aulas por eles seguidas em suas sujeições institucionais.

A análise da Sondagem 1 e do questionário final parece indicar que os estudantes estão familiarizados em assistir a videoaulas disponibilizadas na internet no site de compartilhamento de vídeos YouTube para sanar dúvidas, principalmente de conteúdos das disciplinas da graduação em Matemática, o que corresponde a um ponto positivo, uma vez que esses mesmos estudantes são capazes de avaliar essas aulas e abordar equívocos existentes, o que corresponde a um dos elementos que podem auxiliar na construção das videoaulas.

É importante sublinhar que essa familiaridade também permitiu que os participantes identificassem algumas condições de sua utilização, a saber: a possibilidade da escolha das videoaulas, a atemporalidade que este recurso proporciona e também por ser um material de suporte para os estudantes. Além disso, os participantes apontaram como restrições: os problemas técnicos e os conteúdos não confiáveis que este material pode trazer.

Após a oficina, no questionário final, além das condições já mencionadas, os participantes salientaram a facilidade de acesso das videoaulas e a possibilidade de poderem assistir a elas quantas vezes forem necessárias. Ainda segundo os participantes, existem restrições de ordem didática, ou seja, para eles, ainda é difícil planejar a construção de uma videoaula, utilizar a mesa digitalizadora e trabalhar com alguns programas desconhecidos, o que indica a necessidade de introduzir e tratar explicitamente essas questões nos cursos de formação inicial e contínua de professores.

\section{REFERÊNCIAS}

BORBA, Marcelo de Carvalho; SILVA, Ricardo Scucuglia R. da; GADANIDIS, George. Fases das tecnologias digitais em Educação Matemática: sala de aula e internet em movimento. Belo Horizonte: Autêntica, 2014.

BROUSSEAU, Guy. Glossaire de quelques concepts de la théorie des situations didactiques en mathématiques, 2010. Disponível em: https://bit.ly/2X58utW. Acesso em 05 dez. 2019. 
CAPES.CAPES recebe primeiras propostas de mestrado EaD [2019]. Disponível em: https://bit.ly/3100BFw. Acesso em: 10 dez. 2019.

CHEVALLARD, Yves. Ostensifs et non-ostensifs dans l'activité mathématique, 1994. Disponível em: https://bit.ly/ 3h02nCw. Último acesso em: 16 dez. 2018.

CHEVALLARD, Yves. Le développement actuel de la TAD: pistes et jalons, 2007. Disponível em: http://yves.chevallard. Último acesso em: 16 dez. 2018.

CHEVALLARD, Yves. La TAD face au professeur de mathématiques, 2009. Disponível em: https://bit.ly/3jSHeZu. Último acesso em: 16 dez. 2018.

CHEVALLARD, Yves. Le sujet apprenant entre espace et dispositif. Commentaires depuis la théorie anthropologique du didactique, 2010. Disponível em: https://bit.ly/309Z07N. Último acesso em: 28 jul. 2019.

CHEVALLARD, Yves. Conditions et contraintes de la recherche en didactique des mathématiques: un témoignage, 2011. Disponível em: https://bit.ly/30WSDPw. Último acesso em: 16 dez. 2018.

GODOY, Arilda Schmidt. Introdução à pesquisa qualitativa e suas possibilidades. RAE - Revista de Administração de Empresas, São Paulo, v. 35, n. 2, p. 57-63, 1995.

HONÓRIO, Luiz Gonzaga Hugo. Sala de aula invertida: uma abordagem na aprendizagem de matemática. Dissertação (Mestrado Profissional em Educação Matemática). Universidade Federal de Juiz de Fora, Juiz de Fora, 2017. Disponível em: https://bit.ly/3jYa4lf. Último acesso em 12 de agosto de 2019.

KENSKI, Vani Moreira. Educação e tecnologias: o novo ritmo da informação. Campinas: Editora Papirus. 2007.

LAMBERTI, Denise Di Giovanni. Número natural: conhecimentos de/para professores polivalentes em um curso de especialização. 2014. 221 f. Tese (Doutorado em Educação) - Pontifícia Universidade Católica de São Paulo, São Paulo, 2014. Disponível em: https://bit.ly/2CYvlv7. Último acesso em 12 de agosto de 2019.

MACEDO, Marcos Antônio de. Manifestação geométrica das formas indeterminadas de funções: situações didáticas apoiadas na tecnologia. 2015. 118 f. Dissertação (mestrado) - Universidade Federal do Ceará, Centro de Ciências, Programa de Pós-Graduação em Ensino de Ciências e Matemática, Fortaleza-CE, 2015.

MACHADO, Diogo Vaz. Aplicação de videoaulas complementares e a análise do seu emprego no processo de ensino-aprendizagem em física no Ensino Médio. Dissertação (mestrado em Ensino de Física) - Universidade Federal do Rio de Janeiro, Rio de janeiro, 2017.

MORAIS, Daiane Aparecida Miliossi. Uma aplicação de vlogs nas aulas de estatística na educação básica. 2017. 77 f. Dissertação (Mestrado em Ensino de Matemática) - Universidade Tecnológica Federal do Paraná, Londrina, 2017.

MUNIZ, S. C. S. A inclusão de surdos nas aulas de Matemática: uma análise das relações pedagógicas envolvidas na tríade Professora - Intérprete - Surdo. 2018. 113 f. Dissertação (Mestrado em Educação Matemática) - Universidade Estadual de Santa Cruz, Ilhéus, 2018. 
NASSERALA, Alessandro Mendonça. Elaboração e descrição de situações didáticas com amparo na sequência Fedathi: 0 caso da integral imprópria. 2014. 135 f. Dissertação (mestrado) - Universidade Federal do Ceará, Centro de Ciências, Programa de Pós-Graduação em Ensino de Ciências e Matemática, Fortaleza-CE, 2014. Disponível em: https://bit.ly/2DjEKm1. Último acesso em 11 de agosto de 2019.

OLIVEIRA, Alexandre. STADLER, Pâmella de Carvalho. Videoaulas: uma forma de contextualizar a teoria na prática, 2014. Disponível em: https://bit.ly/2X8bXIf. Último acesso em: 14 dez. 2018.

PATRIARCA, F.H. Contribuições do Programa M@tmídias para a integração de tecnologia às aulas de trigonometria no Ensino Médio. Dissertação (Mestrado em Educação Matemática) Programa de Pós Graduação em Educação Matemática da Universidade Anhanguera de São Paulo, 2016.

PONTES, R. R. de. A Educação de Jovens e Adultos e a Matemática: delineando trilhas alternativas para 0 ensino de operações básicas. 2013. 84f. Dissertação (Programa de Pós-Graduação em Ensino de Ciências e Educação Matemática - PPGECEM) - Universidade Estadual da Paraíba, Campina Grande, 2013.

SILVA, I. P. da. Estilos de aprendizagem e materiais didáticos digitais nos cursos de Licenciatura em Matemática a distância. 2014. 122p. Dissertação (Programa de Pós-Graduação em Ensino de Ciências e Educação Matemática PPGECEM) - Universidade Estadual da Paraíba, Campina Grande, 2014.

SPANHOL, Greicy Kelli; SPANHOL, Fernando José. Processos de produção de vídeo-aula. Revista Novas Tecnologias na Educação, Florianópolis, v. 7, n. 1, jul. 2009. Disponível em: https://bit.ly/2Ex5bFJ. Acesso em: 14 dez. 2018.

RECEBIDO EM: 14 dez. 2019

CONCLUÍDO EM: 05 jun. 2020 
